\title{
Floating houses: an adaptation strategy for flood preparedness in times of global change
}

\author{
P. Strangfeld \& H. Stopp \\ Department of Building Physics, \\ Brandenburg Technical University, Germany
}

\begin{abstract}
The rising sea-level and the frequency of devastating floods have already increased in a considerable way. At the same time, the population is continuously rising, along with the demand for adequate housing and sufficient space. In this context the so-called floating houses are a future-oriented solution for settlements along coastlines and river districts or on little islands.

In highly industrialized countries which export products or the associated licenses it is an opportunity for the development and construction of floating houses. Up to now in most cases the floating objects are built on pontoons as usual buildings on a fixed ground. The special boundary conditions caused by water waves, water chemistry and climate components should be considered in order to prevent damage. Concomitantly the floating objects bring chances for mobility and use of alternative energies due to the water environment.

In Lusatia, a landscape in the eastern part of Germany southeast of Berlin, a lot of former lignite open-cast mines were filled with water and the worldwide largest artificial lake landscape was created among others by the assistance of the International Building Exhibition "Fürst-Pückler-Land". Different types of floating houses have already been built. The department Building Physics of the university BTU-CS has carried out a lot of investigations with regard to materials, energy use and climate boundary conditions by means of measurements and numerical simulations. Besides, water as a building ground must be cost effective and exhibit an affordable floating architecture.
\end{abstract}

Keywords: floods, urban strategies, floating house, heat exchanger. 


\section{Present global situation}

\subsection{Population}

Contrary to the German and European situation, the global population is growing (fig. 1). Above all, the aspiration level increases unrestrained in our society also with regard to the demand for living room. For instance in Germany 70 ha of land per day are used additionally for building in spite of the decreasing population in this country.

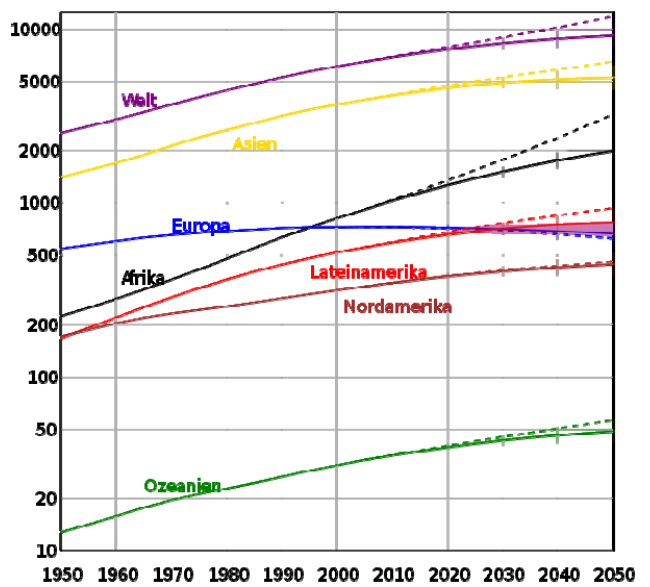

Figure 1: Prognosis of the increase in millions of the worldwide population.

\subsection{Climate change}

Independent of the knowledge of the reasons for climate change, the sea level is rising and endangers the infrastructure of settlements in many regions (fig. 2).
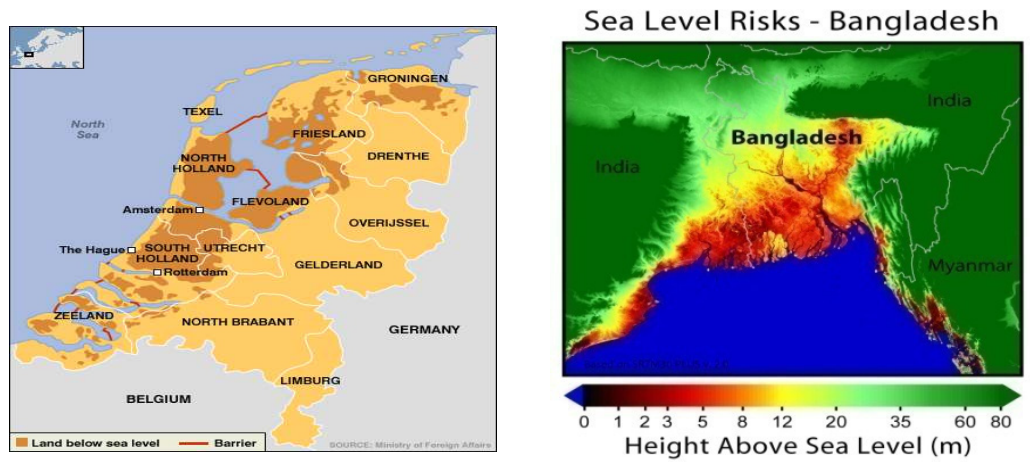

Figure 2: Examples for the effect of sea level rising in the Netherlands and Asia. 


\section{Floating houses}

\subsection{General situation}

Floating houses have a long history [1]. The technique and architecture of these buildings depend on climate boundary conditions, culture and raw materials which were available in various places. Nowadays one can find exquisite examples of floating buildings all over the world (fig. 3).
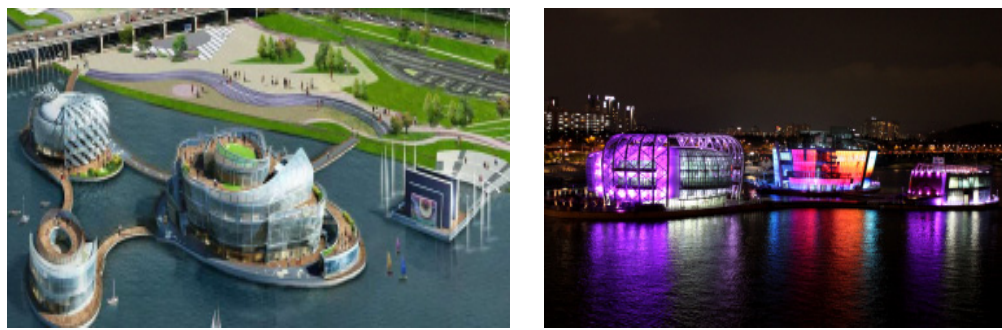

Figure 3: Seoul, floating amusement park opened 2011, Hangang river at night.

\subsection{Examples in Germany}

The following figures represent examples of buildings in Germany floating on lakes of former opencast mines.
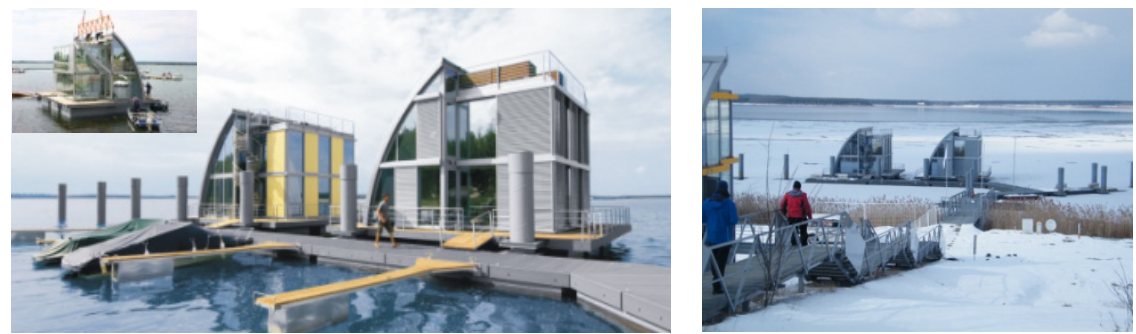

Figure 4: Floating houses type "Ar-che" in the Lusatian landscape.
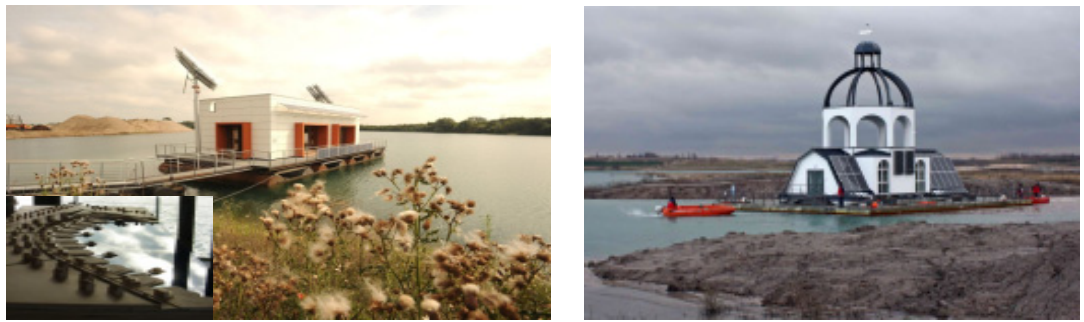

Figure 5: $\quad$ Floating research station on a former opencast gravel mining (left); Floating church on a former lignite opencast mining (right). 


\section{Adaptation}

\subsection{Material and construction}

\subsubsection{Materials}

Building materials used especially for pontoons are highly dependent on the quality of the surrounding water in addition to economic reasons (e.g. the $\mathrm{pH}$ value of mining lakes plays a major role in the corrosion of steel and concrete).

\subsection{Construction}

Floating houses are built on mobile ground. The buoy in fig. 9, installed on the lake of a former opencast lignite mine, records the water waves data and other sensors the effects to the construction of floating houses.

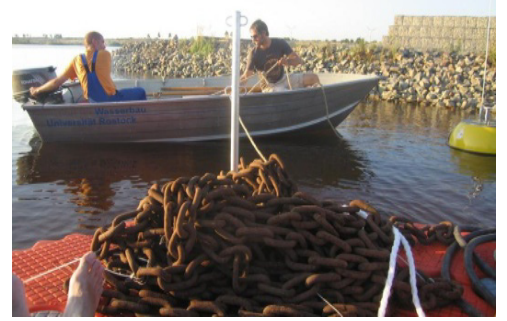

Figure 6: Installation of a buoy for recording the parameters of water waves by GPS -technology.

Another considerable load for a construction is the frost load of the pontoons and piles (fig. 7a). By means of so-called heat pipes alternative energy is used to avoid or at least to reduce the frost action upon the piles. Fig. $7 \mathrm{~b}$ displays such a manufactured heat pipe for a pile and figure 8 shows its installation with the help of a crane.

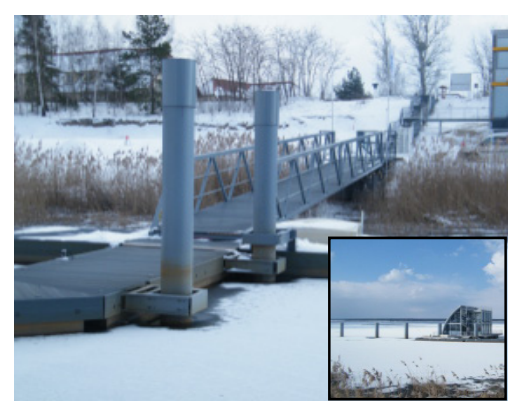

a

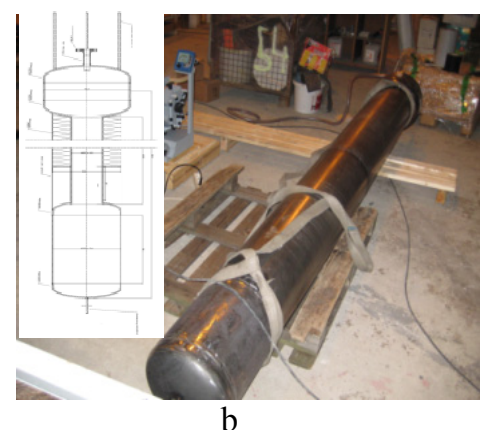

Figure 7: a: Piles subjected to freezing conditions. b: Prefabricated heat pipe. 

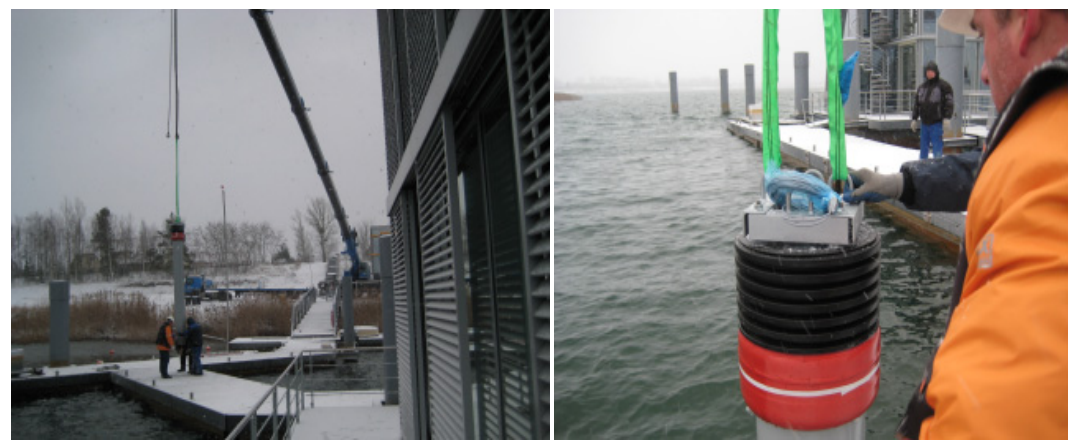

Figure 8: Installation of the heat pipe by means of crane work.

\subsection{Self-sufficiency}

\subsubsection{Water supply, sewage and waste disposal}

Autonomous building is an important prerequisite for a largely economic implementation of floating houses. Drinking water supply and wastewater are part of a field with major recent advances. Decisive impulses have been shaped by space technology.

\subsubsection{Energy supply}

\section{- Spiral heat exchanger}

The virtually unlimited amount of surrounding water provides new opportunities for the use of alternative energies. Figure 9 displays images during experiments for a spiral heat exchanger and the thermal response method. Figure 10 depicts results for the hygrothermal characteristics of the spiral heat exchanger by using numerical simulation. Assembly of the heat exchanger into the pontoon of the "Ar-che"-type floating house is shown in fig. 11. In this case the exchange of heat energy is reduced.
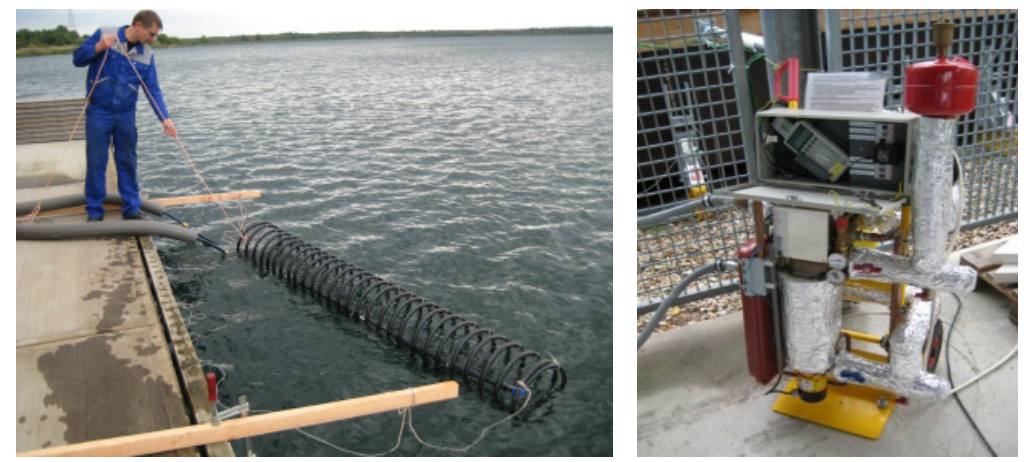

Figure 9: Investigation of the performance parameters of a heat exchanger with the thermal response method. 

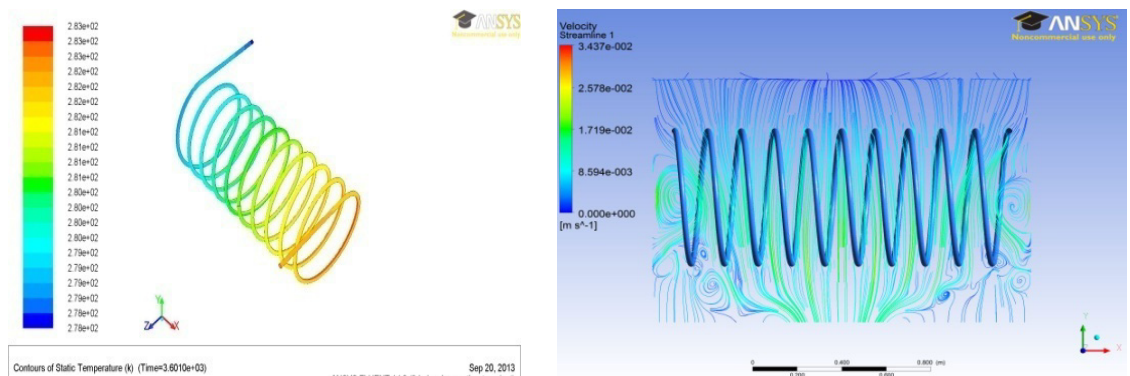

Figure 10: Calculated temperature distribution of a spiral heat exchanger (left), velocity distribution of the exchanger caused by buoyancy (right).
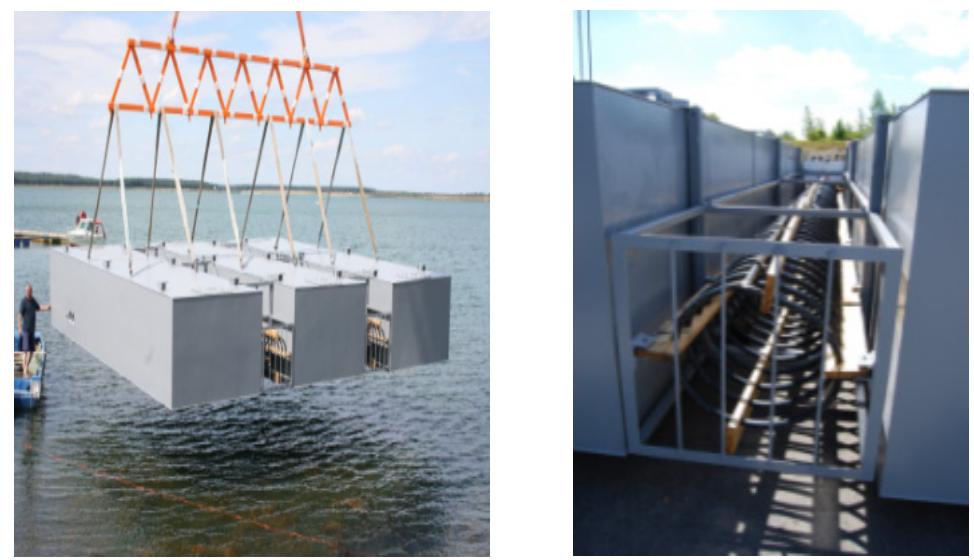

Figure 11: Assembly of the heat exchanger into the pontoon by crane.

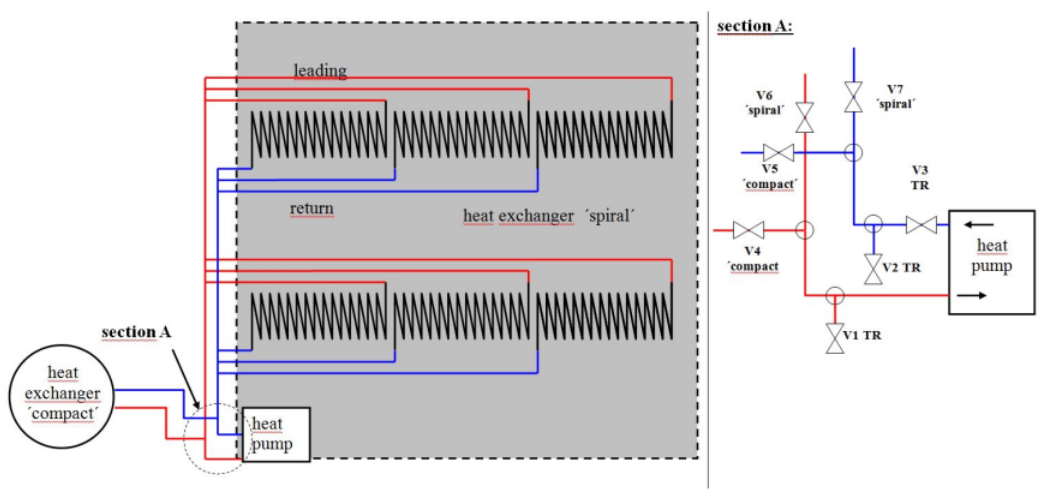

Figure 12: Scheme of the arrangement of six heat exchangers, valves and heat pump. 


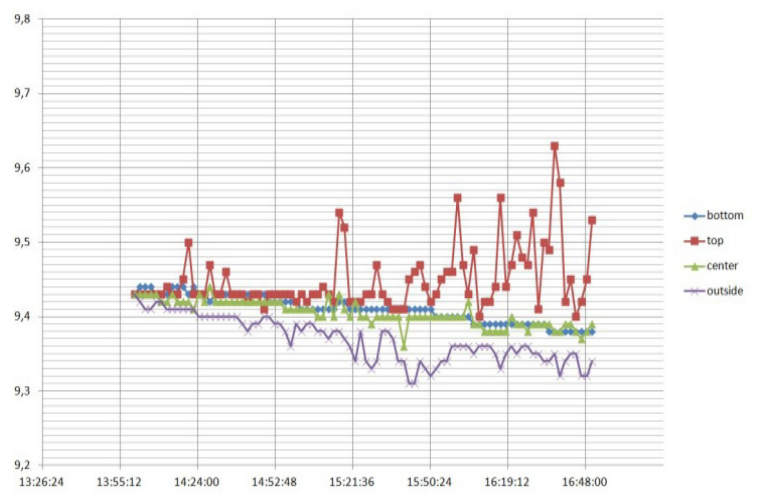

Figure 13: Water-temperature course at different measuring points.

\section{- Compact heat exchanger}

In contrast to the spiral heat exchanger, a compact shape requires less space for the same heat power. By means of numerical simulations an optimal arrangement is to be found with regard to heating in wintertime and cooling in the summer.
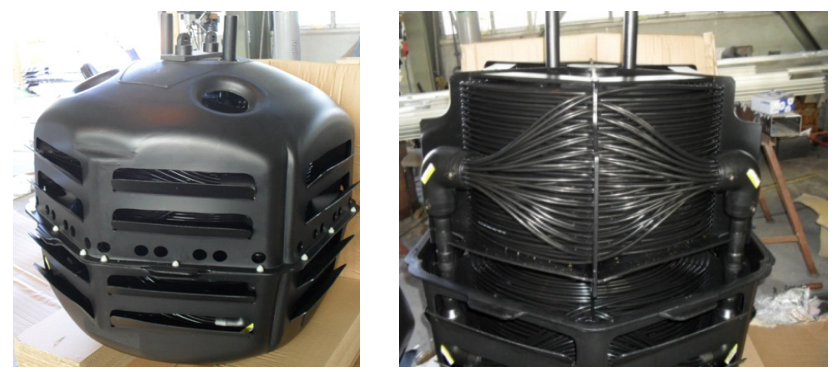

Figure 14: Heat exchanger of the Fa. Frank GmbH in Germany.

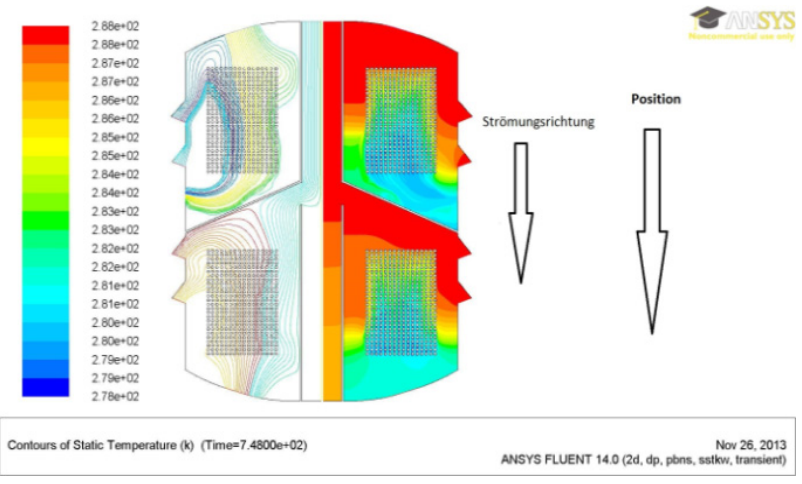

Figure 15: Temperature distribution in a heat exchanger. Heating mode in wintertime, surrounding water: $15^{\circ} \mathrm{C}$, sole temperature: $5^{\circ} \mathrm{C}$. 


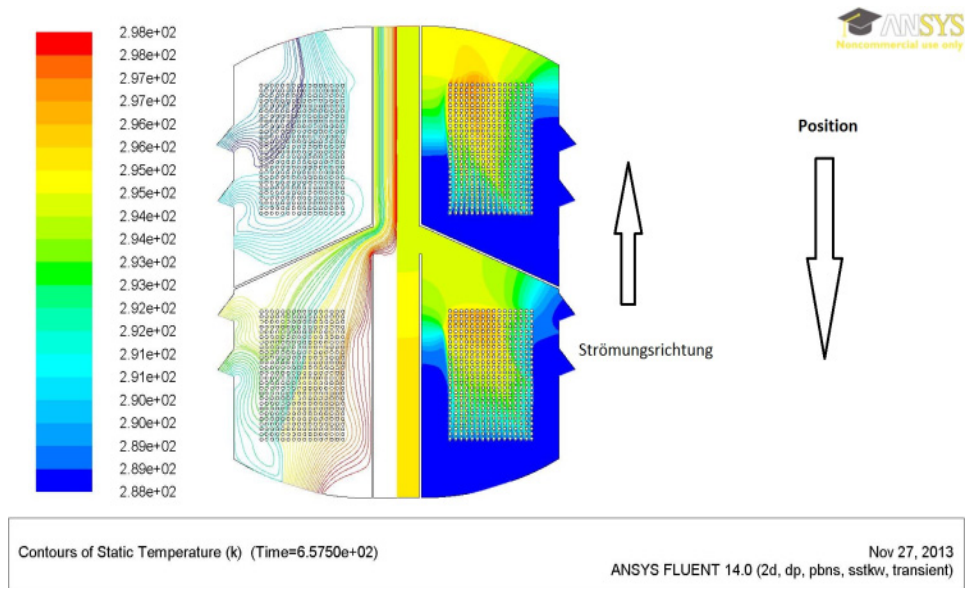

Figure 16: Temperature distribution in a heat exchanger. Heating mode in summer, surrounding water: $15^{\circ} \mathrm{C}$, sole temperature: $25^{\circ} \mathrm{C}$.

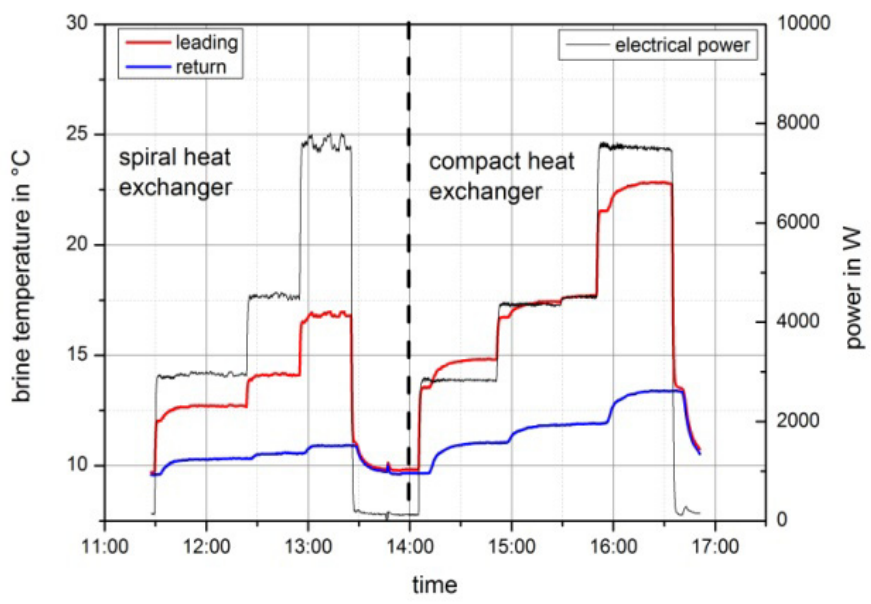

Figure 17: Measuring results of the thermal response method. Left: spiral heat exchanger, right: compact heat exchanger - temperature of surrounding water: $9.8^{\circ} \mathrm{C}$.

\section{- Heat storage}

Solar energy can be stored in the pontoon's space in connection with the classic solar thermal energy. It is also possible to collect the solar energy directly through a transparent, insulating cover in a floating storage box (fig. 18) [2]. In the latter one the detection of temperature distribution is of interest (fig. 19). 


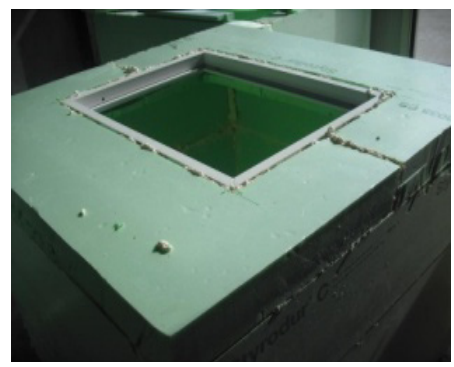

Figure 18: Floating box with a cover of heat-insulating glass for experiments.

The temperature distribution is calculated with and without the convection influence upon the sea water.

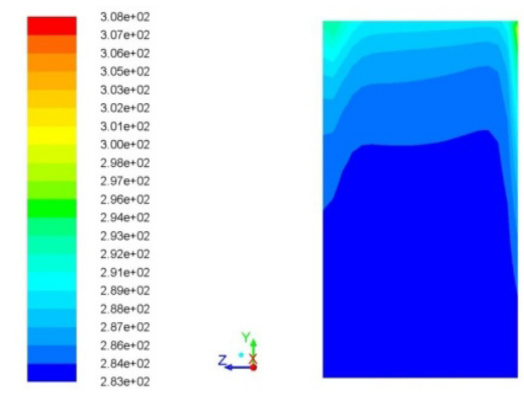

Contours of Static Temperature $(k)($ Time $=3.30200+04)$

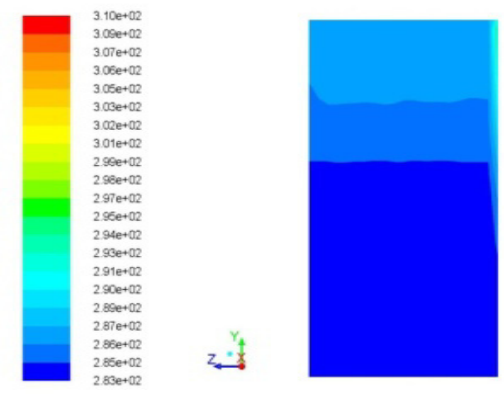

Contours of Stafic Tenperature (k) (Time=3 2090e+04)

Figure 19: Figure 19: The influence of the asymmetric solar radiation on the water surface (left) is eliminated by convection within the water (right).
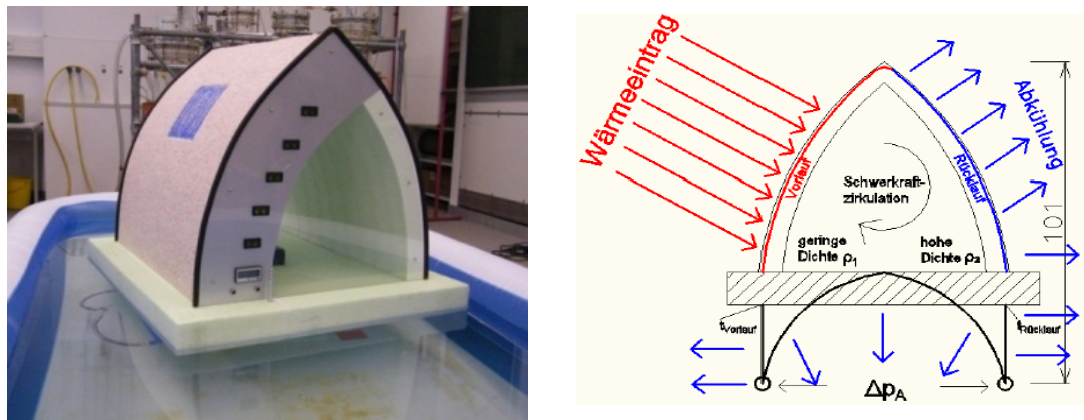

Figure 20: Investigation of heating and cooling of building envelopes by means of water flowing through the structure caused by different densities due to the asymmetric effect of solar direct/ diffuse radiation and long-wave emission. 


\section{Outlook}

Figure 21 depicts the potential of floating houses. Thanks to its mobility principle, a floating object can be transported to another location after fulfilling its purpose. For instance a floating stadium is used for another purpose after a football championship. Nowadays amphibious buses already travel among islands or between the canals of Amsterdam and the Schiphol airport (fig. 22).

Another possibility is buildings floating up in the case of floods if water occurs. It could be an adaptation strategy for flood preparedness near river districts in the future.
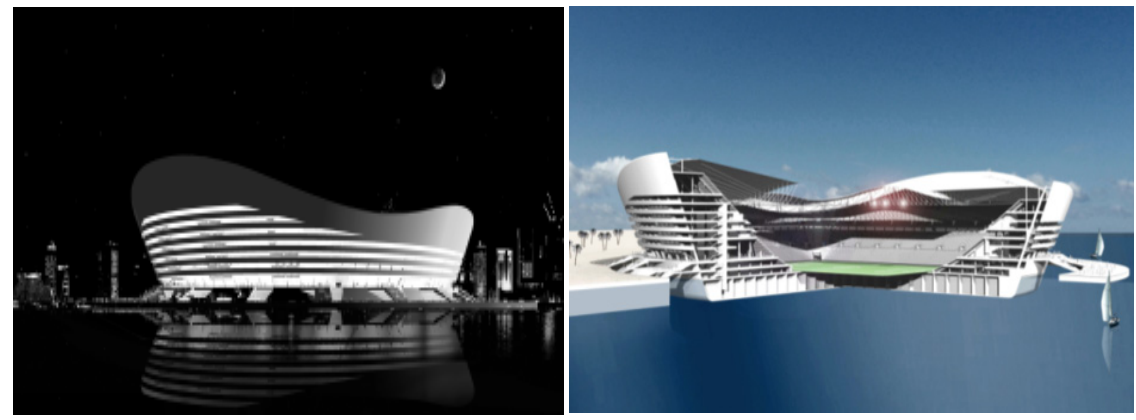

Figure 21: Design of a floating soccer stadium for the World Cup 2022 in Qatar, Architectural Office Düsseldorf, Peter Knoebel.
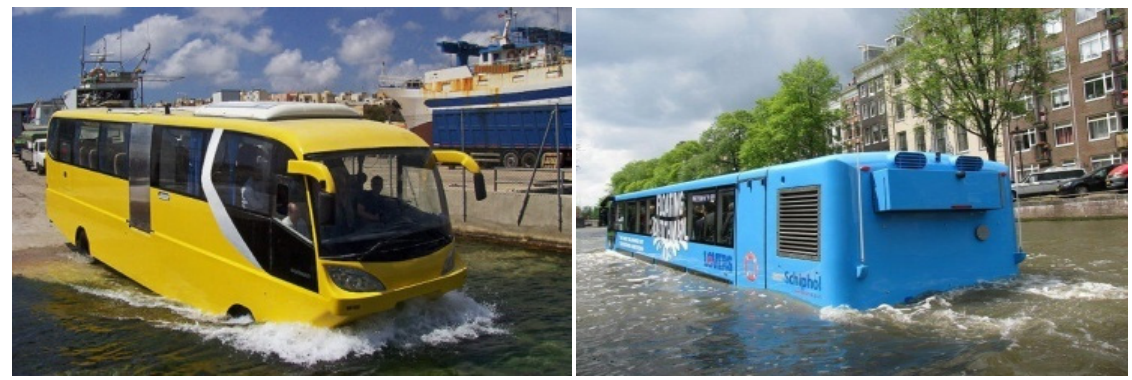

Figure 22: Amphibious buses in Budapest and Amsterdam as rational means of public transport, without the need for a ferry [3].

\section{References}

[1] Stopp, H.; Strangfeld, P.: Schwimmende Wohnbauten, Beuth Verlag, Berlin-Zürich-Wien 2012.

[2] Harnath, M., Heating and water supply of floating houses in compliance with energy issues, Master thesis, University of Appl. Sciences, Hochschule Lausitz (FH), 2011.

[3] www.floatingdutchman.nl, www.toursales.com/Floating-Bus. 